\title{
DEVIASI FORMULASI ROMANCE DALAM NOVEL ELLE ET LUI KARYA MARC LÉVY
}

\author{
Tania Intan \\ Universitas Padjadjaran \\ tania.intan@unpad.ac.id \\ Ferli Hasanah \\ Universitas Padjadjaran \\ ferli.hasanah@unpad.ac.id
}

\begin{abstract}
Abstrak
Penelitian ini bertujuan untuk mengungkap adanya deviasi formulasi romance pada novel Elle et Lui karya Marc Lévy. Pendekatan metodologis yang digunakan adalah analisis struktural dengan perspektif kajian sastra feminis. Landasan teoretis yang menjadi kerangka penelitian ini di antaranya gagasan Radway, Modlesky, serta Gill dan Herdierckerhoff, yang diapropriasi untuk mengupas aspek-aspek naratif romance yang meliputi alur, tokoh, dan sudut pandang. Hasil penelitian menunjukkan bahwa ada penyimpangan formulasi terutama pada komponen alur dan sudut pandang meskipun novel ini berakhir bahagia sesuai dengan pola romance. Bila genre romance umumnya berfokus pada protagonis perempuan seabagai penggerak cerita, novel Elle et Lui (dan juga ternyata pada novel-novel Marc Lévy lainnya) cenderung berpusat pada protagonis laki-laki yang meskipun digambarkan memiliki kelemahan, namun tetap berkarakter pahlawan dan teladan. Narator pada novel tersebut merupakan orang ketiga tunggal yang maha tahu dan dapat berada di beberapa tempat sekaligus, sehingga tidak sesuai dengan formulasi romance standar. Deviasi yang terjadi dapat diargumentasikan sebagai strategi Marc Lévy untuk keluar dari formulasi standar sebuah novel romance yang pada umumnya ditulis oleh perempuan, dan juga karena karakter penulisannya yang sinematografis.
\end{abstract}

Kata kunci: deviasi, formulasi romance, Marc Lévy

\begin{abstract}
This study aims to reveal the deviation of the romance formulation in the novel Elle et Lui by Marc Léry. The methodological approach used is structural analysis with the perspective of feminist literary studies. The theoretical basis of this research framework includes the ideas of Radway, Modlesky, and Gill and Herdierckerhoff, which are appropriated to explore aspects of narrative romance which include plot, character, and point of view. The results showed that there was a deviation in the formulation especially in the flow and point of view component even though the novel ended happily according to the pattern of romance. Whereas the romance genre generally focuses on female protagonists as story movers, Elle et Lui (and also turns out to be on other Marc Léry novels) tends to focus on male protagonists who, despite being described as having weaknesses, are still characterized by heroes and role models. The narrator in the novel is an all-knowing third person and can be in several places at once, so it is not in accordance with standard romance formulations. Deviations that occur can be argued as Marc Léry's strategy to come out of the standard formulation of a romance novel that is generally written by women, and also because of its cinematographic writing character.
\end{abstract}

Keywords: deviation, romance formulation, Marc Lévy 


\section{PENDAHULUAN}

Pada masa lalu, romance, menurut kajian Regis yang dikutip Lee (2008: 53), merupakan karya fiksi yang menceritakan kisah percintaan atau pertunangan seorang atau beberapa tokoh perempuan. Namun kini, romance cenderung mengisahkan perjuangan pasangan untuk dapat hidup bersama. Genre romance berasal dari kultur Eropa dan hingga saat ini masih sangat digemari oleh banyak kalangan, termasuk di Perancis.

Marc Lévy adalah salah satu penulis laki-laki Perancis yang paling terkenal selain Guillaume Musso, Thierry Cohen, dan Laurent Gounelle. Ia lahir pada tanggal 16 Oktober 1961 di Boulogne-Billancourt. Sebelum mulai menulis novel pada usia 37 tahun, ia bekerja sebagai arsitek, dan kemudian menjadi aktor dan produser film. Marc Lévy merupakan penulis novel bertema percintaan yang sangat produktif. Ia menerbitkan satu novel untuk setiap tahunnya sejak tahun 2003, dan mendapatkan penghargaan sastra seperti Prix Goya du premier roman untuk novelnya Et si c'était vrai (2000) yang telah diterjemahkan ke dalam 49 bahasa dan dicetak sebanyak 35 juta kopi. Novel tersebut kemudian difilmkan pada tahun 2005 dengan judul Just Like Heaven dengan sutradara Steven Spielberg. Di usianya yang ke 53 tahun, Marc Lévy telah menjual lebih dari 33 juta eksemplar novelnya ke seluruh dunia (Garcia, 2015). Ia juga dinobatkan sebagai penulis nomor satu Perancis dalam sepuluh tahun berturut-turut dari thun 2003-2013 oleh Le Figaro (Sari, 2019:3).

Karya Marc Lévy lainnya yang terkenal di antaranya Où es-tu? (2001), Sept jours pour une éternité ... (2003), Toutes ces choses qu'on ne s'est pas dites (2008), La Première Nuit (2009), Un sentiment plus fort que la peur (2013), Elle et lui (2015), dan Une fille comme elle (2018). Beberapa penghargaan lain yang pernah diraihnya adalah Prix Littéraire Lucien Barrière du Festival du Cinéma Américain de Deauville (2000), Prix Yves Gibeau (2004), Prix Evasion (2005), Prix Emotion (2006), dan Prix International (2010). Novel-novel karya Marc Lévy yang selalu menjadi best-sellers adalah bacaan yang ringan dengan mengangkat tema yang sederhana seperti percintaan, keluarga, dan persahabatan. Meskipun demikian, publik Perancis pada umumnya sangat menyukai karyanya yang berkarakteristik romance modern dan selalu masuk dalam daftar karya yang paling banyak dibaca (Astuti, 2017: 2).

Dalam konteks karya sastra populer, Regis (2003: 1) mendefinisikan romance sebagai genre le plus populaire et le moins respecté 'genre yang paling populer dan yang paling tidak dihargai'. Dibandingkan dengan genre novel populer lainnya seperti novel detektif, science-fiction, atau kisah fantastik, kritik terhadap genre ini memang lebih gencar [dan pedas] terutama karena alasan suspens yang minim di dalamnya (Gray, 2000). Ceritanya pun mudah ditebak menurut Pritchard (Hall, 2004), karena selalu berakhir bahagia (Happily Ever After). Namun, menurut Lévy (2010), yang dikutip Garcia (2015), [sebagai penulis laki-laki] ia tidak berkeberatan menulis kisah sederhana bertema percintaan karena baginya, "l'amour compte plus que le Goncourt" 'cinta lebih berarti daripada [penghargaan sastra] Goncourt'.

Sesederhana apapun, Michaels (2007: 1) berargumentasi bahwa sebuah romance selalu menarasikan kisah seorang perempuan 'héroine' dan seorang laki-laki 'héros' yang berusaha untuk bersama walaupun ada masalah yang membuat mereka harus berpisah. Cinta yang mereka rasakan satu pada yang lainnya adalah jenis yang hanya muncul sekali dalam seumur hidup 'the love they feel for each other is the sort that comes 
along only once in a lifetime'. Kesadaran tentang hal inilah yang mengarahkan keduanya pada komitmen dan harapan untuk hidup bahagia selamanya sampai akhir hayat mereka. Konsep tersebut melekat erat sebagai formulasi romance, sebagaimana dinyatakan Sabudu (2017: 2) dengan mengutip rumusan dari Romance Writers American (2010-2013).

Dalam romance standar, menurut Modleski (1996: 36), alur cerita selalu ditampilkan sebagai berikut: seorang perempuan muda, tidak berpengalaman, berpenampilan 'biasa' bertemu dengan seorang laki-laki tampan, kaya, berumur 10 atau 15 tahun lebih tua darinya. Karena sebab-sebab yang bervariasi, tokoh laki-laki biasanya mengolok-olok, sinis, menghina, memusuhi dan bahkan bersikap brutal sehingga membuat tokoh perempuan bingung. Pada akhirnya tokoh laki-laki ini mengungkapkan cinta pada tokoh perempuan. Tokoh perempuan menerimanya dan kesalahpahaman pun diselesaikan.

Kisah seperti ini biasanya diatur untuk terjadi dalam "ruang sihir" yang menjadi latar tempat bagi tokoh perempuan secara sosial mengalami masalah hingga harus pergi jauh dari teman dan keluarga untuk pulih dari trauma atau mungkin terbangun dari koma (yang menempatkan dirinya berada di sebuah villa atau kastil). Cerita kemudian dibangun di sekitar serangkaian rintangan yang harus diatasi agar tokoh laki-laki dan tokoh perempuan itu saling jatuh cinta walaupun ada perbedaan kelas, bangsa, atau ras yang mengganggu, termasuk sifat keras kepala keduanya yang membuat mereka menjadi saling membenci (Gill, R., \& Herdieckerhoff, 2006: 490). Narasi romantis lalu berkembang melalui tahap permusuhan, perpisahan, dan rekonsiliasi yang membawa serta perubahan pribadi seorang laki-laki tegar menjadi emosional dalam menyatakan cinta pada tokoh perempuan, yang kemudian berdampak pada pemulihan identitas sosial baru bagi tokoh perempuan (Pearce, L., \& Stacey, 1995).

Secara substansial, tahap pengaluran tersebut dapat berdialog dengan skema naratif khas novel bertema percintaan yang disusun Radway (Radway, 2006: 134) sebagai berikut: (1) awalnya identitas sosial tokoh perempuan rusak, (2) kemudian tokoh perempuan itu bereaksi secara antagonis terhadap seorang bangsawan. (3) Laki-laki bangsawan menanggapi kemarahan tokoh perempuan dengan sikap ambigu, (4) yang ditafsirkan tokoh perempuan sebagai bukti minat seksual murni terhadap dirinya. (5) Tokoh perempuan kemudian menanggapi perilaku tokoh lakilaki itu dengan marah atau dingin. (6) Tokoh laki-laki membalas dengan menghukum tokoh perempuan, sehingga (7) tokoh laki-laki dan tokoh perempuan secara fisik dan/ atau emosional dipisahkan. (8) Tokoh laki-laki tersebut lalu memperlakukan tokoh perempuan dengan lembut, dan (9) tokoh perempuan menanggapi dengan hangat tindakan tokoh laki-laki. (10) Tokoh perempuan itu menafsirkan kembali perilaku ambigu tokoh laki-laki sebagai dampak dari luka sebelumnya. (11) Tokoh laki-laki tersebut secara terbuka menyatakan cintanya dan menunjukkan kesungguhannya kepada tokoh perempuan dengan tindakan yang sangat lembut.

(12) Tokoh perempuan merespons secara seksual dan emosional, (13) dan akhirnya identitas tokoh perempuan dipulihkan.

Menurut Radway (2006: 140), ada dua perspektif standar yang selalu dihadirkan pada tokoh laki-laki dalam romance. Pertama, dia harus memiliki status teladan atau luar biasa untuk menjadi pahlawan. Kedua, laki-laki itu pada awalnya jahat dan kemudian bertobat karena mengalami pembelajaran. Hal ini membentuk 
pola harapan yang menyiratkan suatu kenyataan tentang suami atau pasangan dalam perkawinan para perempuan pembaca. Karena sebagian besar pembacanya adalah perempuan, romance pada umumnya diceritakan dari sudut pandang tokoh perempuan, baik sebagai pencerita orang pertama atau ketiga (Shepherd, 2007). Narator ikut berperan di dalam cerita sebagai tokoh, sehingga ia tidak bersifat omniscient 'maha tahu' atau omnipresent 'hadir di mana saja', pengetahuannya pun terbatas hanya pada apa yang ia lihat, dengar, atau pelajari. Dengan demikian, sifat penceritaannya berkesan intim, subjektif, dan dapat bersifat konfesional/ pengakuan layaknya sebuah buku harian atau otobiografi.

Penelitian ini selanjutnya akan menganalisis salah satu novel Marc Lévy yang berjudul Elle et Lui. Novel tersebut telah menjadi objek penelitian Hidayat (2015) dengan pendekatan psikologi sastra, dengan mengkaji penyebab kecemasan pada dua tokoh utama dan manifestasi pertahanan diri yang dilakukan untuk mengendalikan kecemasan tersebut. Hasil penelitian menunjukkan pemicu kecemasan yaitu pertentangan Id dan Super Ego, serta tidak terpenuhinya kasih sayang sebagai salah satu kebutuhan dasar manusia. Untuk mengendalikan kecemasan, tokoh utama melakukan mekanisme pertahanan diri substitusi, sublimasi, represi, dan reaksi formasi. Kajian lain dalam bidang linguistik dilakukan Sari (2019) pada novel Elle et Lui namun tidak memiliki relevansi dengan penelitian ini.

Berbeda dengan penelitian-penelitian terdahulu tersebut, penelitian ini dilakukan untuk mencermati adanya deviasi pada formulasi romance di dalam novel Elle et Lui. Permasalahan penelitian difokuskan pada elemen-elemen konstruktif dari teks naratif di dalam novel tersebut dan melihat kesesuaiannya [atau ketidak sesuaiannya] dengan formulasi standar dari sebuah novel bertema percintaan. Kajian romance ini diharapkan dapat memberi nilai kebaruan khususnya dalam penelitian dengan perspektif sastra feminis.

\section{METODE PENELITIAN}

Penelitian ini mengkaji novel Elle et Lui, karya keenam Marc Lévy yang diterbitkan pada tanggal 5 Februari 2015 oleh penerbit Robert Laffont-Versilio dengan jumlah 350.000 eksemplar. Novel seharga 21,5-euro yang terdiri dari 166 halaman versi elektronik ini berkisah tentang kisah romantis seorang laki-laki dan seorang perempuan yang berada dalam relasi pertemanan namun kemudian terjebak dalam perasaan cinta dan terkendala dalam pengungkapannya. Latar tempat yang digunakan dalam novel ini adalah kota-kota besar seperti London, New York, Paris, dan Seoul. Elle et Lui termasuk ke dalam novel yang paling banyak dicari pembaca di Perancis dan menjadi best-seller tahun 2015 (Sari, 2019: 3).

Metode yang digunakan dalam penelitian ini adalah analisis deskriptif kualitatif dengan pendekatan kajian struktural dan perspektif sastra feminis sesuai landasan teoretis yang digunakan.

Data untuk penelitian dikumpulkan dari kata, frasa, dan kalimat yang dikutip dari novel yang telah dipilih. Setelah dikategorisasi sesuai dengan pembagian bahasan yaitu alur dan tokoh, selanjutnya dilakukan penerjemahan, dan dieksplorasi dalam analisis dengan menggunakan teori yang relevan. 


\section{HASIL DAN PEMBAHASAN}

Bagian analisis ini diuraikan menjadi dua bagian, yaitu: konstruksi narasi novel dengan tema percintaan untuk membahas aspek alur dan sudut pandang, serta karakteristik romance pada aspek tokoh dan latar yang mempelajari bagaimana para tokoh utama ditampilkan dan ruang tempat mereka dipertemukan.

\subsection{Konstruksi Narasi Novel dengan Tema Percintaan}

Hidayat (2015: 1) memaparkan bahwa melalui interaksi di antara manusia [heteroseksual atau homoseksual], dapat terjalin hubungan pertemanan yang selanjutnya berpotensi menimbulkan kedekatan dan ketertarikan antarpersonal. Perasaan tersebut jika dikembangkan dapat mengarah pada persahabatan, keintiman, dan juga hubungan romantis. Guerro dan Mongeau (2008) menjelaskan bahwa relasi percintaan memang dapat muncul dari berbagai macam situasi seperti perkenalan secara tiba-tiba atau dari hubungan pertemanan yang telah lama dijalin.

Pada setiap romance 'standar', cerita biasanya dibangun melalui tokoh utama perempuan, namun pada novel Elle et Lui, yang lebih dominan justru adalah peran tokoh utama laki-laki. Paul (Lui 'dia laki-laki') adalah seorang penulis novel berkebangsaan Amerika yang memutuskan pindah ke Paris. Ia berpacaran dengan penerjemahnya, Kyong, namun mereka jarang sekali bertemu karena kesibukan masing-masing. Sementara itu, di Inggris, seorang aktris pendatang baru bernama Mia (Elle 'dia perempuan'), mulai jenuh dengan kehidupannya karena hubungannya yang hambar dengan sang suami, David. Mia memutuskan pergi ke Paris dan tinggal bersama Daisy, sahabatnya. Paul dan Mia dipertemukan oleh sebuah situs perkenalan di internet, dan masing-masing berkomitmen untuk tidak saling jatuh cinta meskipun keduanya benar-benar saling menyukai.

Dari ringkasan cerita tersebut, berikut ini telah disusun 13 sekuen dari formulasi romance menurut Radway (2006: 134), dan sekaligus kesesuaian atau ketidaksesuaiannya dengan sekuen-sekuen pada novel Elle et Lui.

Tabel 3.1.1

Formulasi Romance dalam Alur Cerita Novel Elle et Lui

\begin{tabular}{ccc}
\hline No. & Sekuen dengan & Sekuen dalam Novel Elle et Lui \\
Sekuen & Formulasi Romance & \\
\hline
\end{tabular}

1 Identitas sosial tokoh perempuan

Mia, seorang aktris terkenal dari Inggris, rusak. merasa sangat jenuh dengan hidupnya. Hubungannya dengan suaminya, David, juga tidak harmonis. Mia pun melarikan diri ke Paris, untuk tinggal bersama sahabatnya, Daisy dan bekerja sebagai juru masak di sebuah restoran.

\begin{tabular}{rll}
\hline Tokoh perempuan & Secara tidak sengaja, Mia dan Paul \\
itu bereaksi secara & dipertemukan di situs perkenalan. Paul \\
antagonis terhadap & adalah seorang penulis Amerika yang \\
seorang bangsawan. & sedang berada di Paris untuk mencari \\
& inspirasi. Paul sudah memiliki kekasih, \\
& Kyong, yang juga adalah penerjemahnya, \\
& namun mereka sangat jarang bertemu. Pada
\end{tabular}




\begin{tabular}{|c|c|c|}
\hline & & $\begin{array}{l}\text { pertemuannya dengan Paul, Mia dengan } \\
\text { antusias menanyakan hal-hal pribadi } \\
\text { sehingga membuat laki-laki itu canggung. } \\
\text { Mia pun merasa malu dan memutuskan } \\
\text { untuk pergi. }\end{array}$ \\
\hline 3 & $\begin{array}{l}\text { Laki-laki bangsawan } \\
\text { menanggapi } \\
\text { kemarahan tokoh } \\
\text { perempuan dengan } \\
\text { sikap ambigu. }\end{array}$ & $\begin{array}{l}\text { Paul memperbaiki sikapnya dan kesalah } \\
\text { pahaman di antara mereka pun berakhir. } \\
\text { Selanjutnya mereka dapat berbincang } \\
\text { dengan lebih nyaman. Setelah pertemuan } \\
\text { itu, mereka pun bertemu lagi beberapa kali. }\end{array}$ \\
\hline 4 & $\begin{array}{l}\text { Tokoh perempuan } \\
\text { menafsirkan } \\
\text { tanggapan itu } \\
\text { sebagai bukti minat } \\
\text { seksual murni tokoh } \\
\text { laki-laki terhadap } \\
\text { dirinya. }\end{array}$ & $\begin{array}{l}\text { Mia menyadari dirinya yang tertarik pada } \\
\text { Paul, demikian juga halnya dengan Paul. } \\
\text { Namun, keduanya terhalang oleh situasi } \\
\text { masing-masing, Mia sudah memiliki suami } \\
\text { di Inggris, dan Paul memiliki kekasih di } \\
\text { Korea. Mia dan Paul pun berusaha } \\
\text { mempertahankan hubungan pertemanan di } \\
\text { antara mereka dan meyakinkan diri bahwa } \\
\text { mereka tidak saling mencintai. }\end{array}$ \\
\hline 5 & $\begin{array}{l}\text { Tokoh perempuan } \\
\text { kemudian } \\
\text { menanggapi } \\
\text { perilaku tokoh laki- } \\
\text { laki itu dengan } \\
\text { marah atau dingin. }\end{array}$ & $\begin{array}{l}\text { Tidak terjadi. } \\
\text { Pada pertemuan yang kesekian kalinya, Mia } \\
\text { bersiap untuk pergi ke apartemen Paul, } \\
\text { namun ternyata David menjemputnya. Mia } \\
\text { pun pergi dengan suaminya itu. Namun } \\
\text { kemudian Mia melarikan diri lagi dan } \\
\text { menyusul Paul ke Korea untuk menghadiri } \\
\text { publikasi novel terbarunya. }\end{array}$ \\
\hline 6 & $\begin{array}{l}\text { Tokoh laki-laki } \\
\text { membalas dengan } \\
\text { menghukum tokoh } \\
\text { perempuan. }\end{array}$ & $\begin{array}{l}\text { Tidak terjadi. } \\
\text { Di Korea, Paul menyadari bahwa Kyong, } \\
\text { penerjemah sekaligus kekasihnya itu, telah } \\
\text { mengubah isi novel yang ia tulis menjadi } \\
\text { sama sekali berbeda. Dengan demikian, } \\
\text { karya yang telah dicetak dan meledak itu } \\
\text { bukan benar-benar karyanya. Diwarnaioleh } \\
\text { pertentangan batin tersebut, Paul terus } \\
\text { didampingi oleh Mia. }\end{array}$ \\
\hline 7 & $\begin{array}{l}\text { Tokoh laki-laki dan } \\
\text { tokoh perempuan } \\
\text { secara fisik dan/ } \\
\text { atau emosional } \\
\text { dipisahkan. }\end{array}$ & $\begin{array}{l}\text { Setelah acara itu berakhir, Mia yang } \\
\text { cemburu karena kedekatan Paul dengan } \\
\text { Kyong, meninggalkan laki-laki itu dengan } \\
\text { pesan berisi ucapan terima kasih atas } \\
\text { kebersamaan mereka selama ini. Mia } \\
\text { menyatakan keharusan bagi mereka untuk } \\
\text { berpisah karena ia tidak ingin mengganggu } \\
\text { Paul dengan kehidupannya yang rumit. }\end{array}$ \\
\hline 8 & $\begin{array}{l}\text { Tokoh laki-laki } \\
\text { tersebut lalu }\end{array}$ & $\begin{array}{l}\text { Paul segera mencari Mia di Paris, di semua } \\
\text { tempat yang pernah mereka kunjungi }\end{array}$ \\
\hline
\end{tabular}




\begin{tabular}{|c|c|c|}
\hline & $\begin{array}{l}\text { memperlakukan } \\
\text { tokoh perempuan } \\
\text { dengan lembut. }\end{array}$ & $\begin{array}{l}\text { bersama, tapi perempuan itu ada di } \\
\text { manapun. Editor Paul kemudian } \\
\text { menunjukkan surat kabar yang memuat foto } \\
\text { Paul dan Mia yang menyatakan bahwa Mia } \\
\text { adalah aktris terkenal Inggris yang } \\
\text { diketahui berselingkuh. Paul yang baru } \\
\text { menyadari situasi Mia yang sebenarnya } \\
\text { menemui Daisy untuk menyampaikan } \\
\text { pesan. }\end{array}$ \\
\hline 9 & $\begin{array}{l}\text { Tokoh perempuan } \\
\text { menanggapi dengan } \\
\text { hangat tindakan } \\
\text { tokoh laki-laki. }\end{array}$ & $\begin{array}{l}\text { Tidak terjadi. } \\
\text { Mia tidak pernah lagi datang. Paul hanya } \\
\text { mendapat kabar dari Daisy bahwa Mia telah } \\
\text { pulang ke Inggris dan mengurus } \\
\text { perceraiannya dengan David. Selain itu, } \\
\text { Daisy menyatakan ada foto yang } \\
\text { menunjukkan Mia sedang mengantre di } \\
\text { Museum Louvre. }\end{array}$ \\
\hline 10 & $\begin{array}{l}\text { Tokoh perempuan } \\
\text { itu menafsirkan } \\
\text { kembali perilaku } \\
\text { ambigu tokoh laki- } \\
\text { laki sebagai dampak } \\
\text { dari luka } \\
\text { sebelumnya. }\end{array}$ & $\begin{array}{l}\text { Tidak terjadi. } \\
\text { Paul terus mencari perempuan yang } \\
\text { dicintainya itu ke semua tempat yang } \\
\text { mungkin didatangi Mia, tapi tidak ada hasil. } \\
\text { Paul justru mendapat berita bahwa } \\
\text { novelnya akan mendapatkan penghargaan } \\
\text { sastra bergengsi. }\end{array}$ \\
\hline 11 & $\begin{array}{l}\text { Tokoh laki-laki } \\
\text { tersebut secara } \\
\text { terbuka menyatakan } \\
\text { cintanya dan } \\
\text { menunjukkan } \\
\text { kesungguhannya } \\
\text { kepada tokoh } \\
\text { perempuan dengan } \\
\text { tindakan yang } \\
\text { sangat lembut. }\end{array}$ & $\begin{array}{l}\text { Tidak terjadi. } \\
\text { Yang terjadi adalah Paul datang ke acara } \\
\text { penghargaan itu dan menyampaikan bahwa } \\
\text { novel itu bukan benar-benar karyanya. } \\
\text { Novel itu lebih tepat disebut ditulis kembali } \\
\text { oleh Kyong, penerjemahnya. Paul pun } \\
\text { merasa lega dengan pengakuannya itu. }\end{array}$ \\
\hline 12 & $\begin{array}{l}\text { Tokoh perempuan } \\
\text { merespons secara } \\
\text { seksual dan } \\
\text { emosional. }\end{array}$ & $\begin{array}{l}\text { Pada akhirnya, Mia menemui Paul dan } \\
\text { mengungkapkan rasa cintanya. Sebaliknya, } \\
\text { Paul juga menyatakan cinta dan menerima } \\
\text { Mia apa adanya. }\end{array}$ \\
\hline 13 & $\begin{array}{l}\text { Identitas sosial } \\
\text { tokoh perempuan } \\
\text { dipulihkan. }\end{array}$ & $\begin{array}{l}\text { Mia menyatakan telah bercerai dengan } \\
\text { David, sehingga dirinya dan Paul dapat } \\
\text { bersama. Mereka pun pergi ke San Francisco } \\
\text { untuk memulai hidup baru. }\end{array}$ \\
\hline
\end{tabular}

Dari tiga belas sekuen yang harus hadir untuk mengonstruksi sebuah romance standar menurut Radway, tabel 3.1.1 menunjukkan adanya penyimpangan dengan ketidak hadiran lima sekuen yaitu sekuen-sekuen nomor 5, 6, 9, 10, dan 11. 
Situasi awal dan akhir dari novel Elle et Lui memang telah memenuhi kriteria sekuensial romance, yang dimulai dari rusaknya identitas sosial tokoh perempuan (1) dan berakhir pada pulihnya identitas sosial tokohtersebut (13). Adapun lima sekuen yang tidak terpenuhi merupakan bagian dari serangkaian rintangan yang harus diatasi agar tokoh laki-laki dan perempuan itu dapat bersama, yaitu narasi tentang perpisahan dan rekonsiliasi.

Dari tabel sekuen tersebut juga terungkap dominasi peran tokoh laki-laki dibandingkan dengan tokoh perempuan. Paul digambarkan lebih bersikap aktif dalam menghadapi masalahnya, yang berkaitan dengan proses penulisan novelnya yang terhambat karena kekurangan ide $(2,6,11)$, hubungannya dengan Kyong yang tidak kondusif (sekuen 2, 6), dan perasaannya pada Mia yang tidak terungkapkan dengan baik (sekuen 3, 4, 5, 8, 9, 10, 12).

Tabel 3.1.1 juga memperlihatkan bahwa perjuangan untuk dapat hidup bersama tidak hanya dilakukan oleh Paul tapi juga Mia. Tokoh perempuan ini memperlihatkan upaya untuk dapat hidup bersama dengan laki-laki yang dicintainya itu baik sebagai teman $(2,3,4,5,6,7)$ maupun sebagai kekasih $(12,13)$. Upaya kedua tokoh untuk dapat bersama ini memungkinkan cerita diakhiri dengan bahagia, sesuai dengan formula standar romance dan kriteria fin heureuse 'akhir cerita yang bahagia' yang disyaratkan Peyroutet (2001: 8).

Romance pada umumnya diceritakan dari sudut pandang tokoh perempuan, baik sebagai pencerita orang pertama atau ketiga (Shepherd, 2007), karena pada umumnya ditulis oleh perempuan untuk publik perempuan. Akan tetapi, pada novel Elle et Lui terungkap bahwa narator adalah sosok maha tahu yang berada di luar cerita. Dari judul novel, telah terlihat jelas bahwa pencerita menggunakan kata ganti elle (dia, perempuan) yang merujuk pada tokoh Mia dan lui (dia, laki-laki) pada Paul. Walaupun menjadi berkesan netral/ tidak berpihak, narator ini cenderung mewakili pikiran-pikiran yang berasal dari protagonis laki-laki. Dengan jenis sudut pandang ini, narator mengetahui semua fakta yang ada, peristiwa yang dialami para tokoh, maupun pemikiran dan perasaan mereka. Une focalisation zéro atau vision par en-dessus seperti ini dapat digunakan oleh Marc Lévy karena cerita menjadi berkesan hidup, tidak monoton, dan potensial untuk dikembangkan secara sinematografis.

Dari pembahasan terhadap alur ini, dapat disimpulkan bahwa terdapat deviasi pada alur novel Elle et Lui yang tidak memenuhi setiap sekuen yang wajib hadir dalam sebuah romance. Demikian pula dengan narasi yang dibawakan oleh orang ketiga tunggal, yang berdampak pada karakter penceritaan.

\subsection{Karakteristik Romance pada Aspek Penokohan}

Bila pada umumnya romance berfokus pada protagonis perempuan sebagai penggerak cerita, novel-novel yang ditulis pengarang laki-laki cenderung lebih terpusat pada protagonis laki-laki. Tokoh Paul Barton sebelumnya telah muncul sebagai tokoh pendukun pada novel pertama Marc Lévy, Et si c'était vrai ... (2000) dan Vous revoir (2005) yang sengaja dimunculkannya kembali par désir et par plaisir 'keinginan dan kesenangan' pribadi si penulis (Orieul, 2015). Protagonis ini pun secara langsung diasosiasikan dengan dirinya dan pengalamannya sebagai penulis. Seperti Marc Lévy, Paul Barton juga adalah seorang arsitek yang kemudian memilih untuk menulis novel bertema romantis. 
Après avoir publié son premier roman, Paul avait décidé de mettre sa carrière $d^{\prime}$ architecte entre parenthèses. Écrire lui avait offert une liberté insoupç,onnable. Rien dans sa démarche n'avait été prémédité. Il avait simplement pris plaisir à noircir des pages, près de trois cents lorsqu'il avait tapé le mot « fin ». (Lévy, 2015: 16)

Setelah menerbitkan novel pertamanya, Paul memutuskan untuk menghentikan karirnya sebagai arsitek. Menulis menawarinya kebebasan yang tak terbayangkan. Tidak ada yang direncanakan. Dia hanya menikmati menghitamkan halaman, hampir tiga ratus ketika ia mengetik kata "tamat" (Lévy, 2015: 16)

Selama tinggal di Paris, alih-alih merasa bahagia dan dapat menulis dengan lancar, Paul justru digambarkan mengalami kesepian akut. Ia memang berhasil menulis lima buah novel, tapi hal itu tidak membuatnya senang. Paul justru merindukan pekerjaan lamanya sebagai arsitek dan kehidupannya yang dulu menyenangkan bersama teman-temannya. Ia juga memilih menjauhi kehidupan glamor sebagai penulis terkenal (hal. 21). Hubungan cintanya dengan Kyong juga tidak terjalin baik karena mereka sangat jarang bertemu, hanya empat belas hari dalam setahun (hal. 22).

Sebuah romance standar, menurut Modleski (1996: 36), selalu menggunakan alur cerita yang mempertemukan seorang perempuan muda, tidak berpengalaman, berpenampilan 'biasa' bertemu dengan seorang laki-laki tampan, kaya, berumur 10 atau 15 tahun lebih tua darinya. Hal yang berbeda ditunjukkan novel Elle et Lui. Mia, atau nama aslinya Mélissa Barlow, adalah seorang aktris yang tidak dijelaskan penampilannya, namun cerdas dan sensitif (hal. 8). Ia telah menikah dengan David, seorang aktor ternama, namun tidak merasa bahagia. Mia juga tidak terlalu antusias dengan pekerjaannya sebagai aktris yang mengharuskannya selalu hidup di dalam kepura-puraan (Hidayat, 2015: 27).

Tu commences à être appreéciée un peu partout sur le continent, tes cachets sont indécents par les temps qui courent et si ce film obtient le succès que je suppose, tu seras bientôt l'actrice la plus cotée de ta génération. Alors, un peu de patience, je t'en prie. Nous sommes d'accord? Dans quelques semaines les propositions américaines tomberont comme cette pluie. Tu vas entrer dans la cour des grandes. (Lévy, 2015: 2)

Kamu mulai dikenal di hampir seluruh tempat di Inggris, honormu akan membaik seiring berjalannya waktu dan jika film ini sukses seperti yang seharusnya, kamu akan menjadi aktris papan atas pada generasimu. Jadi, sabar sedikit, aku mohon padamu. Kita sepakat, kan? Dalam beberapa minggu permintaan dari Amerika akan berjatuhan seperti hujan ini. Kamu akan masuk dalam jalur kesuksesan. (Lévy, 2015: 2)

Mia digambarkan sebagai pribadi yang mendambakan kebebasan tanpa halangan dari profesinya sebagai artis dan perkawinannya yang membosankan. "Désobeir est une chose que je n'ai guère eu le loisir de faire depuis deux ans." "Tidak patuh adalah kesenangan yang tidak lagi aku dapatkan sejak dua tahun lalu." (hal. 52) Ia 
pun tinggal bersama sahabatnya Daisy, dan bekerja sebagai juru masak di sebuah restoran untuk lari dari permasalahannya. Perubahan profesi dari aktris menjadi juru masak ini menegaskan adanya hasrat yang kuat pada diri protagonis perempuan itu untuk beralih dari ruang publik ke ruang domestik dengan tujuan menghindari sorotan media.

Kondisi Paul yang tidak puas dengan keadaannya karena hambatan dalam menulis dan merasa kesepian, serta Mia yang tidak bahagia dengan pekerjaan dan perkawinannya ternyata mempertemukan mereka berdua. Vavasseur (t.t.) kemudian menautkan kedua tokoh, sebagaimana ditulisnya sebagai review untuk novel tersebut.

Elle est actrice. Lui, écrivain.

Elle s'appelle Mia. Lui, Paul.

Elle est anglaise. Lui, américain.

Elle se cache à Montmartre. Lui vit dans le Marais.

Elle a beaucoup de succès. Lui, pas vraiment.

Elle est même une star. Mais lui ne le sait pas.

Elle se sent seule. Lui aussi.

Il la fait rire. Elle enchaîne les maladresses.

Elle ne doit pas tomber amoureuse. Lui non plus.

Dia (perempuan) seorang aktris. Dia (laki-laki), penulis.

Dia (perempuan) bernama Mia. Dia (laki-laki), Paul.

Dia (perempuan) orang Inggris. Dia (laki-laki), orang Amerika.

Dia (perempuan) bersembunyi di Montmartre. Dia (laki-laki), hidup di Le

Marais.

Dia (perempuan) sangat sukses. Dia (laki-laki), tidak terlalu.

Dia (perempuan) bahkan adalah seorang bintang. Namun, dia (laki-laki) tidak mengetahuinya.

Dia (perempuan) merasa sendiri. Dia (laki-laki), juga.

Dia (laki-laki) membuatnya tertawa. Dia (perempuan) melakukan kecerobohan.

Dia (perempuan) tidak boleh jatuh cinta. Dia (laki-laki) juga tidak boleh.

Dari kutipan di atas, telah terlihat bahwa di antara Mia dan Paul lebih banyak terdapat perbedaan, mulai dari profesi, kebangsaan, latar sosial, serta kesuksesan. Yang menjadi kesamaan dan mempersatukan mereka adalah rasa kesepian, keinginan untuk dapat saling menghibur, dan kesadaran bahwa situasi masingmasing tidak mengizinkan bagi mereka untuk berhubungan lebih dekat.

Pasangan dalam romance biasanya dipertemukan dalam 'ruang sihir' (Gill, R., \& Herdieckerhoff, 2006: 490), yang dalam konteks novel Elle et Lui adalah sebuah situs perjodohan. Dua orang yang sedang merasa kesepian itu membutuhkan suatu tempat untuk berinteraksi dengan campur tangan takdir. Pada ruang maya itulah, kedua individu dapat menampilkan sisi terbaik dirinya demi mendapatkan pasangan yang diinginkan. 
- Vous croyez qu'une femme et un homme peuvent devenir amis sans qu'il y ait entre eux la moindre ambiguif é?

- Si l'une sort à peine d'une histoire et que le coeur de l'autre est pris, je pense que oui... En tout cas, raconter sa vie à une inconnue sans craindre d'être jugé est agréable. (Lévy, 2015: 61)

- Anda percaya kalau seorang perempuan dan seorang laki-laki bisa menjadi teman tanpa ada sesuatu yang sedikit ambigu di antara mereka?

- Jika salah satu baru saja keluar dari masalah di masa lalunya dan satu orang lagi hatinya sudah dimiliki orang lain, saya pikir ya ... lagi pula, menyenangkan bisa menceritakan kehidupanmu pada seseorang yang tak dikenal tanpa harus takut dihakimi. (Lévy, 2015: 61)

Pada awalnya, relasi yang dibangun di antara kedua protagonis adalah pertemanan, namun ternyata berkembang menjadi hubungan yang lebih intim. Pada pertemuan mereka yang pertama, Mia memilih untuk membayar makanannya sendiri dan menjaga jarak (hal. 61). Namun sikap seperti itu berubah dan berkembang menjadi perasaan cinta dan nyaman saat berdua dengan Paul. Rasa cemburu pun muncul saat Mia melihat laki-laki itu membahas novelnya secara intens dengan Kyong (hal. 147).

Dalam konteks romance, karakter Paul sebagai prince charming yang datang untuk menyelamatkan 'sang putri' Mia dari berbagai permasalahan terungkap dari tindakan-tindakan penyelamatan yang ia lakukan. Aksi 'heroik' yang ditampilkan protagonis laki-laki itu di antaranya: mengembalikan harga diri Mia yang merasa malu saat pertemuan pertama (hal. 59), memutuskan untuk melupakan Kyong (hal. 143), mencari Mia ke setiap tempat yang pernah mereka kunjungi (hal. 145-146), dan meninggalkan Paris untuk pergi ke San Francisco bersama perempuan yang dicintainya itu (hal. 166). Keteladanan juga ditunjukkan Paul yang dengan jujur mengakui penghargaan sastra untuk karyanya seharusnya ditujukan pada Kyong, bukan dirinya. Ia juga ditampilkan mampu keluar dari berbagai masalah pribadinya tanpa menimbulkan [banyak] konflik.

Adapun wacana perselingkuhan dalam novel Elle et Lui yang [kemungkinan besar] ditujukan pada tokoh Mia dan Paul tidak berkembang dan justru menjadi ambigu. Secara eksplisit, di dalam teks dinyatakan bahwa masing-masing dari pasangan mereka, yaitu David dan Kyong, jauh dari sikap jujur dan setia. Apabila David kerap berselingkuh, maka Kyong berlaku curang dengan memanfaatkan karya-karya Paul untuk menceritakan kisahnya sendiri melalui novel hasil terjemahannya. Perempuan itu menguraikan cerita kekejaman rezim Kim Jong-Un di Korea Utara, tempat Kyong tumbuh besar bersama keluarganya.

Sebuah romance tidak akan memberi kemudahan pada pasangan yang sedang jatuh cinta untuk begitu saja hidup bersama selamanya. Dalam kajian Hidayat (2015: 46-68), ada beberapa penghambat dalam relasi percintaan di antara Paul dan Mia. Dari sisi protagonis perempuan, ada kebimbangan terhadap status perkawinannya dan kecemasan pada masa depan hubungannya dengan Paul. Dari sisi protagonis laki-laki, juga ada ketidak mampuan untuk melupakan kekasihnya dan kebingungan dalam menghadapi sikap tertutup Mia. Namun semua hambatan tersebut dapat diatasi karena kesungguhan cinta di antara keduanya. Hal ini sangat penting 
terealisasi, karena formulasi romance mengharuskan hadirnya akhir cerita yang membahagiakan bagi semua pihak, terutama para pembaca.

\section{PENUTUP}

Penelitian ini menunjukkan bahwa formulasi romance tidak [harus] selalu berlaku sepenuhnya pada novel bertema percintaan. Seluruh pembahasan yang telah dipaparkan memperlihatkan adanya deviasi atau penyimpangan formulasi romance yang relatif besar pada novel Elle et Lui, mulai dari aspek alur, sudut pandang, maupun tokoh. Hal tersebut terungkap dari temuan-temuan bahwa tidak semua sekuen formulasi standar romance dapat dipenuhi novel tersebut. Ada penyimpangan terutama pada komponen alur dan sudut pandang meskipun novel ini berakhir bahagia sesuai dengan pola romance. Bila genre romance umumnya berfokus pada protagonis perempuan seabagai penggerak cerita, novel Elle et Lui (dan juga ternyata pada novel-novel Marc Lévy lainnya) cenderung berpusat pada protagonis laki-laki yang meskipun digambarkan memiliki kelemahan, namun tetap berkarakter pahlawan dan teladan. Narator pada novel tersebut merupakan orang ketiga tunggal yang maha tahu dan dapat berada di beberapa tempat sekaligus, sehingga tidak sesuai dengan formulasi romance standar.

Marc Lévy menyatakan bahwa dalam setiap romance yang ditulisnya, tidak akan ada kejutan besar apapun karena semua kisah cinta sudah seharusnya berakhir bahagia (fin heureuse). Tema percintaan juga merupakan hal yang sederhana namun dapat menjadi menarik bila disampaikan dengan jujur oleh penulisnya. Ia berpendapat, bahwa yang terpenting dari sebuah romance " $n^{\prime}$ est pas la destination, mais bien le voyage" "bukanlah tujuan, tapi yang benar (adalah) perjalanannya'.

\section{DAFTAR PUSTAKA}

Astuti, N. D. (2017). Analisis Struktural-Semiotik Roman Mes Amis Mes Amours karya Marc Lévy. Universitas Negeri Yogyakarta.

Garcia, V. (2015). Elle et Lui, de Marc Levy, passe le test de la page 99. Retrieved April 6, 2020, from https:/ / www.lexpress.fr/culture/livre/elle-lui-de-marclevy-passe-le-test-de-la-page-99_1648210.html

Gill, R., \& Herdieckerhoff, E. (2006). Rewriting the Romance. Feminist Media Studies, 6(4), 478-504. https://doi.org/10.1080/14680770600989947

Gray, P. (2000). Passion on the Page. Time.

Guerrero, L. K., \& Mongeau, P. A. (2008). On becoming "more than friends": The transition from friendship to romantic relationship. In Handbook of relationship initiation (In S. Spre, pp. 175-194). London: Psychology Press.

Hall, M. M. (2004). Wickedly Savage Passions.

Hidayat, R. (2015). Pengendalian Kecemasan Dua Tokoh Utama dalam Novel Elle et Lui karya Marc Lévy. Universitas Padjadjaran.

Lee, L. J. (2008). Guilty Pleasures: Reading Romance Novels as Reworked Fairy Tales. Marvels \& Tales, 22(1), 52-66.

Lévy, M. (2015). Elle et Lui. Paris: Robert Laffont-Versilio.

Michaels, L. (2007). On Writing Romance How to Craft a Novel That Sells: The Essential 
Elements of Writing a Romance Novel (Writer's D). Ohio.

Modleski, T. (1996). Loving with a vengeance: mass-produced fantasies for women. New York: Routledge.

Orieul, A. (2015). Elle et Lui: Marc Levy renoue (enfin) avec la comédie romantique. Retrieved April 6, 2020, from

https:// www.terrafemina.com/culture/livres/articles/53963-elle-et-lui-marclevy-renoue-enfin-avec-la-comedie-romantique.html

Pearce, L., \& Stacey, J. (1995). Romance revisited. New York: New York University Press.

Peyroutet, C. (2001). La Pratique de l'Expression Ecrite. Paris: Nathan.

Radway, J. A. (2006). Reading the romance: women, patriarchy, and popular literature; with a new introduction by the author. Chapel Hill: Univ. of North Carolina Pr.

Regis, P. (2003). A Natural History of the Romance Novel. Philadelphia.

Sabudu, D. (2017). The Formula of Romance (A Study on Erick Wilson's Fire Proof). Kompetisi, 15(2), 1-13.

Sari, F. B. . (2019). Bentuk dan Makna Kata Argot dalam Roman Elle et Lui karya Marc Levy. Universitas Negeri Yogyakarta.

Shepherd, L. (2007). How To Write a Romance Novel: Romantic Fiction Writing Tips, Understand What's Needed to Write a Romantic Love Story. Retrieved July 28, 2019, from How to do things website: http:/ / www.howtodothings.com/hobbies/a4587-how-to-write-a-romancenovel.html

Vavasseur, P. (n.d.). Elle et Lui (Best) (French Edition). Retrieved April 6, 2020, from https:// www.amazon.com/Elle-Lui-Marc-Levy/dp/2266290746. 